\title{
ПРИМЕНЕНИЕ В НАНОМЕДИЦИНЕ И ФАРМАКОЛОГИИ НАНОЧАСТИЦ МЕТАЛЛОВ И ИХ НЕОРГАНИЧЕСКИХ СОЕДИНЕНИЙ, ПОЛУЧЕННЫХ МЕЖФАЗНЫМ И КОНТАКТНЫМ ВЗАИМОДЕЙСТВИЕМ
}

\author{
С. А. Воробьева ${ }^{\square}$, С. Э. Ржеусский ${ }^{2}$
}

${ }^{1}$ Научно-исследовательский институт физико-химических проблем Белорусского государственного университета, Минск, Беларусь

Витебский государственный ордена Дружбы народов медицинский университет, Витебск, Беларусь

\begin{abstract}
Одной из актуальных проблем современной препаративной неорганической химии являются получение и исследование наночастиц металлов и их соединений с заданными морфологией и дисперсностью для использования в медицине, фармакологии, микроэлектронике. Наряду с традиционным осаждением из водных растворов перспективны, но менее изучены межфазный синтез и контактное восстановление. В работе представлены результаты физико-химического исследования наночастиц металлов и их соединений, полученных химическим осаждением из водных растворов, межфазным и контактным взаимодействием. Для иллюстрации использования синтезированных наночастиц в фармакологии и медицине приведены данные по влиянию фазового состава и дисперсности наночастиц меди и оксида меди (II) на их противомикробные свойства и результаты исследования возможности применения магнетитовых магнитных жидкостей для маркирования мезенхимальных стволовых клеток.
\end{abstract}

Ключевые слова: наномедицина, фармакология, нанометаллы, оксиды, сульфиды, магнитные жидкости, стволовые клетки, антимикробные средства

Финансирование: экспериментальные исследования проводились при поддержке Белорусского республиканского фонда фундаментальных исследований (гранты X96-157, Х04-073, Х09-025, X11MC-034).

Благодарности: авторы благодарят Дражину Н. П и Петрову Е. А. за проведение исследований маркированных мезенхимальных стволовых клеток, а также сотрудников лаборатории химии конденсированных сред НИИ физико-химических проблем Белгосуниверситета, принимавших участие в синтезе и исследовании наноразмерных металлов и их соединений.

$\triangle$ Для корреспонденции: Светлана Александровна Воробьева

ул. Ленинградская, д. 14, г. Минск, Беларусь, 220030; vorobyova@bsu.by

Статья получена: 27.06.2018 Статья принята к печати: 28.07.2018

DOI: $10.24075 /$ vrgmu.2018.076

\section{NANOPRTICLES OF METALS AND THEIR INORGANIC COMPOUNDS OBTAINED THROUGH INTERPHASE AND REDOX-TRANSMETALATION INTERACTION: APPLICATION IN MEDICINE AND PHARMACOLOGY}

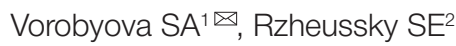

Research Institute for Physical Chemical Problems of the Belarusian State University, Minsk, Belarus

2 Vitebsk State Order Of Peoples' Friendship Medical University, Vitebsk, Belarus

Synthesis of nanoparticles of metals and their compounds with given morphology and dispersity for use in medicine, pharmacology, microelectronics, as well as subsequent research of their properties, is one of the current problems in the field of preparative inorganic chemistry. Interphase synthesis and redox-transmetalation interaction are as promising as the traditional precipitation from aqueous solutions, but not as researched. This study presents the results of a physicochemical analysis of nanoparticles of metals and their compounds obtained through chemical precipitation from aqueous solutions, interphase and redox-transmetalation interactions. Data describing the influence of phase composition and dispersity of copper and copper oxide (II) nanoparticles on their antimicrobial properties, as well as the results of researching the possibility to use magnetite magnetic fluids for mesenchymal stem cells marking, illustrate the application options synthesized nanoparticles find in pharmacology and medicine.

Keywords: nanomedicine, pharmacology, nanometals, oxides, sulfides, magnetic fluids, stem cells, antimicrobial agents Funding: experimental stages of the study were supported by the Belarusian Republican Foundation for Fundamental Research (grants X96-157, X04-073, X09025, X11MS-034).

Acknowledgments: the authors would like to thank N. P. Drazhina and E. A. Petrova for researching the marked mesenchymal stem cells, and fellows of the Laboratory of Condensed Matter Chemistry at the Research Institute for Chemical Physical Problems of the Belarusian State University who participated in the synthesis and research of nanoparticles of metals and their compounds.

$\checkmark$ Correspondence should be addressed: Svetlana A. Vorobyova Leningradskaya 14, Minsk, Belarus, 220030; vorobyova@bsu.by

Received: 27.06.2018 Accepted: 28.07.2018

DOI: 10.24075/brsmu.2018.076

В препаративной неорганической нанохимии интересной в научном и важной в практическом отношении является проблема получения наночастиц металлов и их неорганических соединений с заданной морфологией и дисперсностью, которые в значительной степени определяют свойства и качество разрабатываемых перспективных материалов различного назначения. В связи с этим поиск новых и совершенствование известных 
способов получения наночастиц металлов и их соединений с требуемыми свойствами являются неизменно актуальной научной и технологической задачей.

Применительно к получению наноразмерных металлов и их неорганических соединений наряду с традиционным осаждением из водных растворов, всесторонне и детально исследованным и активно применяющимся химиками, перспективны, но менее изучены межфазный синтез и контактное восстановление, которые мы использовали для получения гидро- и органозолей некоторых металлов, оксидов и солей.

Для иллюстрации применения синтезированных наночастиц в фармакологии и медицине в работе представлены данные по влиянию фразового состава и дисперсности наночастиц меди и оксида меди (II) на их противомикробные свойства, а также результаты исследования возможности применения магнетитовых магнитных жидкостей в маркировании мезенхимальных стволовых клеток (МСК).

\section{Межфазный синтез наноразмерных металлов и их неорганических соединений}

Суть межфазного синтеза заключается в получении металлов и их соединений в результате взаимодействия реагентов, растворенных в различных фазах водноорганических систем, смешивание которых не допускается, в отличие от реакций в микроэмульсиях. Особенность этих реакций в том, что они могут протекать в одной из фаз или на границе их раздела. При этом условия протекания реакции в каждой фазе двухфазной системы существенно различаются, что служит предпосылкой получения неорганических веществ со свойствами, отличными от свойств неорганических веществ, осаждаемых из гомогенных, в частности, водных растворов [1-8].

Результаты физико-химического исследования полученных нами органо- и гидрозолей металлов и их соединений представлены в таблице и работах [2-8].
Анализ препаративных возможностей межсразного синтеза свидетельствует о том, что состояние (осадок, пленка, коллоидный раствор) и область локализации (органическая или водная фраза, граница раздела фраз) продуктов реакции зависят от многих факторов (природы, концентрации и соотношения реагентов, температуры реакции, объема фаз и площади поверхности раздела), что не позволяет в настоящее время сформулировать закономерности межфазного синтеза, общие для соединений различных классов.

Вместе с тем, полученные данные позволяют отметить некоторые особенности межфазного синтеза. K первой особенности можно отнести возможность получения коллоидных растворов без введения в их состав дополнительных поверхностно-активных веществ и стабилизирующих добавок. Частицы дисперсной фазы коллоидных растворов в условиях межфазного синтеза образуются одновременно с образованием поверхностноактивных веществ (олеиновой кислоты или олеата натрия) и стабилизирующих добавок (четвертичных аммониевых соединений), и с этой точки зрения процесс получения коллоидного раствора при межфазном взаимодействии можно рассматривать как самоорганизующийся, когда концентрация поверхностно-активного вещества, необходимая и достаточная для получения коллоидного раствора, создается в процессе синтеза, а не подбирается эмпирическим путем, как, например, при получении ферромагнитных жидкостей.

Другая особенность межфазного синтеза заключается в том, что данный метод позволяет получать неорганические вещества в условиях, существенно более мягких по сравнению с теми, которые используются при синтезе тех же веществ химическим осаждением их водных растворов. В результате, при изменении состава двухфазной системы, например, замене водной фазы на спиртовую и соблюдении всех прочих параметров неизменными, наблюдается образование наночастиц различной морфологии и дисперсности, что было продемонстрировано нами на примере оксида цинка [5].

Таблица. Результаты исследования наночастиц металлов и их соединений, полученных межфазным синтезом в двухсазной системе неполярный растворитель/вода

\begin{tabular}{|c|c|c|c|c|}
\hline Коллоидная дисперсия & $\begin{array}{l}\text { Фаза локализации } \\
\text { продуктов реакции }\end{array}$ & Средний размер частиц, нм & $\begin{array}{c}\text { Максимум полосы оптического } \\
\text { поглощения } \lambda_{\max }, n m\end{array}$ & $\begin{array}{l}\text { Ссылка на } \\
\text { литературу }\end{array}$ \\
\hline $\mathrm{Au}$ & $\begin{array}{c}\text { Органическая, водная или граница } \\
\text { раздела фаз в зависимости от } \\
\text { условий синтеза }\end{array}$ & 2,6 & 514 & 2 \\
\hline $\mathrm{Ag}$ & Органическая & 10,0 & 440 & 3 \\
\hline $\mathrm{Pd}$ & Органическая & 1,4 & 440 & - \\
\hline $\mathrm{Ag} / \mathrm{Pd}$ & Органическая & 2,1 & 430 & - \\
\hline $\mathrm{Ag} / \mathrm{Au}$ & $\begin{array}{c}\text { Органическая, водная или граница } \\
\text { раздела фаз в зависимости от } \\
\text { условий синтеза }\end{array}$ & 4,2 & 470 & - \\
\hline $\mathrm{Cu}$ & $\begin{array}{c}\text { Органическая или водная в зависи- } \\
\text { мости от условий синтеза }\end{array}$ & 10,0 & 575 & - \\
\hline $\mathrm{CuO}$ & Органическая & 3,2 & - & 4 \\
\hline $\mathrm{ZnO}$ & $\begin{array}{c}\text { Органическая или водная в } \\
\text { зависимости от условий синтеза }\end{array}$ & $\begin{array}{c}\text { Форма и размер частиц } \\
\text { зависят от условий синтеза }\end{array}$ & - & 5 \\
\hline CdS & Органическая & 2,0 & 311 & 7 \\
\hline Cus & Органическая & $\begin{array}{c}\text { Форма и размер частиц } \\
\text { зависят от условий синтеза }\end{array}$ & - & - \\
\hline ZnS & Органическая & $\begin{array}{c}\text { Форма и размер частиц } \\
\text { зависят от условий синтеза }\end{array}$ & - & - \\
\hline $\mathrm{Fe}_{3} \mathrm{O}_{4} / \mathrm{Au}$ & Органическая & 12.8 & 590 & 6 \\
\hline $\mathrm{Fe}_{3} \mathrm{O}_{4} / \mathrm{CdS}$ & Органическая & 10,3 & 311 & 7 \\
\hline
\end{tabular}


Кроме того, при введении в одну из фаз полимерного вещества возможно получение практически в одну стадию нанокомпозитов, содержащих наноразмерные частицы, образующиеся непосредственно в полимерной матрице, что предотвращает их агрегирование и, как следствие, позволяет сохранять высокую дисперсность сформировавшихся наночастиц.

Другая интересная особенность межфазного синтеза заключается в возможности его использования для получения бифункциональных магнитных наночастиц $\mathrm{Fe}_{3} \mathrm{O}_{4} / \mathrm{Au}$ и $\mathrm{Fe}_{3} \mathrm{O}_{4} / \mathrm{CdS}$, сочетающих свойства магнитного ядра $\left(\mathrm{Fe}_{3} \mathrm{O}_{4}\right)$ и оптически активных оболочек (Au, CdS) [6-8]. Так, при восстановлении золотохлористоводородной кислоты в двухсазной системе, одна из фраз которой образована коллоидным раствором магнетита, удалось получить нанокомпозиционные системы $\mathrm{Fe}_{3} \mathrm{O}_{4} / \mathrm{Au}$ co структурой «ядро-оболочка» [8].

\section{Получение би- и триметаллических наночастиц контактным взаимодействием}

Другим методом, который использовался нами для получения би- и триметаллических наночастиц, в том числе со структурой «ядро-оболочка» был метод контактного взаимодействия, заключающийся в восстановлении солей металлов металлическими наночастицами, образующими ядро [9]. В отличие от методов получения композитов со структурой «ядро-оболочка» с использованием линкеров, данный способ экспериментально достаточно прост и не требует использования дорогостоящих реактивов для поверхностной функционализации.

В настоящее время нами получены контактным восстановлением и всесторонне исследованы би- и триметаллические наночастицы с использованием в качестве ядра (восстановителя) металлической меди и магнитных наночастиц Fe и FeCo. Полученные результаты показали, что при контактном восстановлении соединений золота и серебра наночастицами FeCo образуются магнитные наночастицы FeCoAu и FeCoAg со структурой «ядро-оболочка» [10]. Формирование оболочек драгоценных металлов на поверхности легко окисляющихся магнитных ядер позволяет предотвратить или уменьшить их окисление и, кроме того, расширяет возможности направленной функционализации образующихся нанокомпозитов, в том числе и для биомедицинских приложений.

\section{Влияние дисперсности и фазового состава на антимикробные свойства медьсодержащих антимикробных средств}

Одним из перспективных направлений создания новых лекарственных средств, обладающих антимикробным действием, является использование в их составе малотоксичных и не вызывающих резистентности наночастиц металлов с выраженной бактерицидной, противовирусной, фунгицидной и иммуномодулирующей активностью.

Как правило, при использовании нанометаллов в качестве фармацевтической субстанции разработчики стремятся к использованию возможно более дисперсных наночастиц, не оценивая при этом затраты на разработку и технологическую адаптацию методов получения сверхдисперсных частиц, которые потенциально могут существенно превышать положительный эффект от их использования. В связи с этим мы исследовали влияние на антимикробную активность фазового состава, морфологии и дисперсности наночастиц металлической меди и оксида меди (II), полученных химическим осаждением из водных растворов в присутствии полиэтиленгликоля [11].

Методика пробоподготовки и результаты исследования антимикробной активности и спектра действия полученных наночастиц детально описаны ранее [12]. В качестве тесткультур использовали грамотрицательные (Escherichia coli), грамположительные (Pseudomonas aeruginosa, Staphylococcus aureus), в том числе спорообразующие (Bacillus subtilis), бактерии и микроскопические грибы (Candida albicans). В качестве лекарственных средств сравнения изучали мази, содержащие хлорамфеникол, хлоргексидин и комбинацию холина салицилата и цеталкония хлорида.

В результате исследования было установлено, что наночастицы меди обладают широким спектром антимикробного действия по отношению $\mathrm{k}$ грамположительным и грамотрицательным бактериям, однако оно менее выражено, чем у мази, содержащей хлорамфеникол. При этом противогрибковые свойства наночастиц меди лишь незначительно уступают таковым лекарственных средств, содержащих хлоргексидин, холина салицилат и цеталкония хлорид.

Анализ зависимости антимикробного эффекта от размеров наночастиц металлической меди, изменяющихся в пределах 14-37 нм, показал, что линейный рост антимикробной активности при уменьшении размера наночастиц меди до 14 нм характерен для образцов с концентрацией медьсодержащей суспензии, не превышающей 0,5 масс.\%. При использовании более концентрированных суспензий (0,75 масс.\%) уменьшение размера частиц с 37 до 14 нм не приводит к увеличению антимикробного эффекта.

\section{Применение магнитных наночастиц для маркирования МСK}

Одним из направлений исследований магнетитовых магнитных жидкостей, синтезируемых в НИИ физикохимических проблем Белорусского госуниверситета, явилось изучение возможности применения магнитных наночастиц для маркирования мезенхимальных стволовых клеток (МСК), которое проводилось совместно с сотрудниками Белорусского государственного медицинского университета (Минск, Беларусь). Среди магнитных наночастиц наиболее перспективными материалами для наномедицины являются наноразмерные оксиды железа (II, III) благодаря относительной простоте их получения, а также низкой цитотоксичности [13]. Известно, что магнитные наночастицы можно использовать для маркировки как мезенхимальных, так и нейронных стволовых клеток с целью их выделения из клеточной суспензии [14-16], концентрирования [17], а также для визуализации и мониторинга методом МРТ [18], что имеет исключительное значение в случае трансплантации стволовых клеток [19].

Детали синтеза магнитных наночастиц, маркирования мезенхимальных стволовых клеток и исследования их свойств подробно описаны в [20, 21]. Для маркирования MCK использовали культуры МСK, выделенные из костного мозга половозрелых белых аутбредных крыс. Магнитные наночастицы оксида железа (II, III) получали химическим осаждением из водных растворов с последующей стабилизацией поверхностно-активными веществами. 
В результате проведенных исследований показано, что синтезированные магнитные наночастицы в концентрации 0,0069 масс.\% характеризуются низкой цитотоксичностью и эффективно маркируют МСK при инкубации в течение 24 ч. Полученные данные свидетельствуют о том, что магнитные наночастицы локализуются в везикулах в цитоплазме клеток и сохраняются в них при пересеве, не оказывая негативного влияния на способность клеток к адгезии, распластыванию и пролиферации, причем магнитные наночастицы при делении клеток распределяются между дочерними клетками. Экспериментально подтверждено, что маркированные магнитными наночастицами стволовые клетки могут быть детектированы in vivo с помощью МРТ.

Следует также отметить, что полученные магнитные наночастицы, стабилизированные олеиновой кислотой и триэтаноламином, обладают рядом преимуществ по сравнению с известными материалами на основе наноразмерных оксидов железа, требующими длительной инкубации со стволовыми клетками или дополнительного использования транспортных агентов, например протаминсульфата, а также отрицательно влияющими на способность стволовых клеток к дифференцировке.

\section{ЗАКЛЮЧЕНИЕ}

Необходимо отметить, что, несмотря на значительные успехи в разработке и исследовании химических основ получения наноразмерных металлов, оксидов и солей, возможность дальнейшего их использования в составе нанокомпозиционных материалов различного назначения зависит от коллективных усилий ученых различных специальностей. Применительно к наномедицине и фармакологии принципиально важно научиться управлять морфологией, дисперсностью и фазовым составом используемых наночастиц с учетом требований к разрабатываемым материалам медицинского назначения и оценить риски их практического использования.

\section{Литература}

1. Xinkui Yangying, Chen Wang. A new two-phase system for the preparation of nearly monodisperse silver nanoparticles Materials Letters. 2008; (62): 4366-8. DOI: 10.1016/j. matlet.2008.07.034.

2. Vorobyova SA, Sobal NS, Lesnikovich Al. Colloidal gold, prepared by interphase reduction. Colloids and Surfaces A: Physicochem Eng Aspects. 2001; (176): 273-7.

3. Lesnikovich Al, Vorobyova SA, Sobal NS. Preparation of silver nanoparticles by interphase reduction. Colloids and Surfaces $A$ Physicochem Eng Aspects. 1999; (152): 375-9.

4. Vorobyova SA, Lesnikovich Al, Mushinskii W. Interphase synthesis and characterization of $\mathrm{CuO}$ in octane. Colloids and Surfaces A: Physicochem Eng Aspects. 1999; (150): 297-300.

5. Vorobyova SA, Lesnikovich Al, Mushinskii W. Interphase synthesis and characterization of zinc oxide. Materials Letters. 2004; (58): 863-6. DOI: 10.1016/j.matlet.2003.08.008.

6. Semenova EM, Vorobyova SA, Lesnikovich Al, Fedotova JA Bayev VG. Fabrication and investigation of magnetite nanoparticles with gold shell. Journal of Alloys and Compounds. 2012; (530): 97-101. DOI: 10.1016/j.jallcom.2012.03.090.

7. Semenova EM, Vorobyova SA, Lesnikovich Al. Synthesis of cadmium sulfide coated magnetic nanoparticles. Physics, Chemistry and Application of Nanostructures: Proceeding of the International Conference. Nanomeeting-2011; 2011 May; Minsk, Belarus. 333-336.

8. Semenova EM, Vorobyova SA, Lesnikovich Al. Interphase synthesis of $\mathrm{Fe}_{3} \mathrm{O}_{4} / \mathrm{CdS}$ core-shell nanoparticles. Optical Materials. 2011; (34): 99-102. DOI: 10.1016/j.optmat.07.008.

9. Lee W, Kim M, Choi J, Park J. Redox-transmetalation process as a generalized strategy for core-shell magnetic nanoparticles. $J$ Amer Chem Soc. 2005; (127): 16090-7. DOI: 10.1021/ja053659j.

10. Bayev VG, Fedotova JA, Vorobyova SA, Svito IA, Ivashkevich OA Tyutyunnikov SI, Kolobylina NN, Guryeva PV. Mössbauer spectroscopy and magnetometry of FeCo-Ag and FeCo-Au nanocomposites synthesized by a redox-transmetalation method. Materials Chemistry and Physics 2018; (216): 349-53. DOI: 10.1016/j.matchemphys.2018.06.031.

11. Auchynnikava AA, Vorobyova SA, Rzheussky SE. Antimicrobial activity of copper nanoparticles depending on the particles size. Physics, Chemistry and Application of Nanostructures: Proceeding of the International Conference. Nanomeeting-2015 2015 May; Minsk, Belarus. 480-3.

12. Ржеусский С. Э., Авчинникова Е. А., Воробьева С. А. Нанодиагностика и антимикробные свойства наночастиц меди. Вестник фармации. 2014; (3): 62-8.

13. Cen L, Neoh KG, Sun J, Hu F et al. Labeling of Adipose Derived Stem Cells by Oleic Acid Modified Magnetic Nanoparticles. Adv Funct Mater. 2009; (8): 1158-66. DOI: 10.1002/adfm.200801670.

14. Wang L, Neoh K-G, Kang E-T et al. Biodegradable magneticfluorescent magnetite/poly(DL-lactic acid-co- $\alpha, \beta$-malic acid) composite nanoparticles for stem cell labeling. Biomaterials. 2010; (13): 3502-11. DOI: 10.1016/j.biomaterials.2010.01.081.

15. Song $\mathrm{M}$, Moon WK, Kim $\mathrm{Y}$ et al. Labeling Efficacy of Superparamagnetic Iron Oxide Nanoparticles to Human Neural Stem Cells: Comparison of Ferumoxides, Monocrystalline Iron Oxide, Cross-linked Iron Oxide (CLIO)- $\mathrm{NH}_{2}$ and tat-CLIO. Korean J Radiol. 2007; (5): 365-71. DOI: 10.3348/kjr.2007.8.5.365.

16. Odabaș S, Sayar F, Güven G et al. Separation of mesenchymal stem cells with magnetic nanosorbents carrying CD105 and CD73 antibodies in flow-through and batch systems. J Chromatogr B. 2008; 861 (1): 74-80. DOI: 10.1016/j.jchromb.2007.11.017.

17. Ito A, Hibino $\mathrm{E}$, Honda $\mathrm{H}$ et al. A new methodology of mesenchymal stem cell expansion using magnetic nanoparticle. Biochem Eng J. 2004; 20 (2-3): 119-25. DOI: 10.1016/j.bej.2003.09.018.

18. Hsiao JK, Tai M-F, Chu H-H et al. Magnetic nanoparticle labeling of mesenchymal stem cells without transfection agent: cellular behavior and capability of detection with clinical $1.5 \mathrm{~T}$ magnetic resonance at the single cell level. Magnet Reson Med. 2007: 71724. DOI: $10.1002 / \mathrm{mrm} .21377$.

19. Zhu J, WuX, Zhang HL. Adult Neural Stem Cell Therapy: Expansion In Vitro, Tracking In Vivo and Clinical Transplantation. Curr Drug Targets. 2005; 6 (1): 97-110. DOI: 10.2174/1389450053345055.

20. Петрова Е. А., Дражина Н. П., Семенова Е. М., Воробьева С. А. Применение магнитных наночастиц для маркирования мезенхимальных стволовых клеток. Вестник БГУ. Серия 2. 2012; (3): 54-9.

21. Дражина Н. П., Петрова Е. А., Семенова Е. М., Воробьева С. А. авторы. Учреждение образования «Белорусский государственный медицинский университет», Учреждение Белорусского государственного университета «Научноисследовательский институт физико-химических проблем», патентообладатели. Концентрат для получения средства витальной маркировки мезенхимальных стволовых клеток. Патент РБ 17804. 15.02.2012. 


\section{References}

1. Xinkui Yangying, Chen Wang. A new two-phase system for the preparation of nearly monodisperse silver nanoparticles Materials Letters. 2008; (62): 4366-8. DOI: 10.1016/j. matlet.2008.07.034

2. Vorobyova SA, Sobal NS, Lesnikovich Al. Colloidal gold, prepared by interphase reduction. Colloids and Surfaces A: Physicochem Eng Aspects. 2001; (176): 273-7.

3. Lesnikovich Al, Vorobyova SA, Sobal NS. Preparation of silver nanoparticles by interphase reduction. Colloids and Surfaces A: Physicochem Eng Aspects. 1999; (152): 375-9.

4. Vorobyova SA, Lesnikovich Al, Mushinskii W. Interphase synthesis and characterization of $\mathrm{CuO}$ in octane. Colloids and Surfaces A: Physicochem Eng Aspects. 1999; (150): 297-300.

5. Vorobyova SA, Lesnikovich Al, Mushinskii W. Interphase synthesis and characterization of zinc oxide. Materials Letters. 2004; (58): 863-6. DOI: 10.1016/j.matlet.2003.08.008.

6. Semenova EM, Vorobyova SA, Lesnikovich Al, Fedotova JA Bayev VG. Fabrication and investigation of magnetite nanoparticles with gold shell. Journal of Alloys and Compounds. 2012; (530): 97-101. DOI: 10.1016/j.jallcom.2012.03.090.

7. Semenova EM, Vorobyova SA, Lesnikovich Al. Synthesis of cadmium sulfide coated magnetic nanoparticles. Physics, Chemistry and Application of Nanostructures: Proceeding of the International Conference. Nanomeeting-2011; 2011 May; Minsk, Belarus. 333-336.

8. Semenova EM, Vorobyova SA, Lesnikovich Al. Interphase synthesis of $\mathrm{Fe}_{3} \mathrm{O}_{4} / \mathrm{CdS}$ core-shell nanoparticles. Optical Materials. 2011; (34): 99-102. DOI: 10.1016/j.optmat.07.008.

9. Lee W, Kim M, Choi J, Park J. Redox-transmetalation process as a generalized strategy for core-shell magnetic nanoparticles. J Amer Chem Soc. 2005; (127): 16090-7. DOI: 10.1021/ja053659j.

10. Bayev VG, Fedotova JA, Vorobyova SA, Svito IA, Ivashkevich OA, Tyutyunnikov SI, Kolobylina NN, Guryeva PV. Mössbauer spectroscopy and magnetometry of FeCo-Ag and FeCo-Au nanocomposites synthesized by a redox-transmetalation method. Materials Chemistry and Physics. 2018; (216): 349-53. DOl: 10.1016/j.matchemphys.2018.06.031.

11. Auchynnikava AA, Vorobyova SA, Rzheussky SE. Antimicrobial activity of copper nanoparticles depending on the particles size. Physics, Chemistry and Application of Nanostructures: Proceeding of the International Conference. Nanomeeting-2015; 2015 May; Minsk, Belarus. 480-3.
12. Rzheusskij SJe, Avchinnikova EA, Vorobyova SA. Nanodiagnostika i antimikrobnye svojstva nanochastic medi. Vestnik farmacii. 2014; (3): 62-8.

13. Cen L, Neoh KG, Sun J, Hu F et al. Labeling of Adipose Derived Stem Cells by Oleic Acid Modified Magnetic Nanoparticles. Adv Funct Mater. 2009; (8): 1158-66. DOI: 10.1002/adfm.200801670.

14. Wang L, Neoh K-G, Kang E-T et al. Biodegradable magneticfluorescent magnetite/poly(DL-lactic acid-co- $\alpha, \beta$-malic acid) composite nanoparticles for stem cell labeling. Biomaterials. 2010; (13): 3502-11. DOI: 10.1016/j.biomaterials.2010.01.081.

15. Song $M$, Moon WK, Kim $Y$ et al. Labeling Efficacy of Superparamagnetic Iron Oxide Nanoparticles to Human Neural Stem Cells: Comparison of Ferumoxides, Monocrystalline Iron Oxide, Cross-linked Iron Oxide (CLIO)- $\mathrm{NH}_{2}$ and tat-CLIO. Korean J Radiol. 2007; (5): 365-71. DOI: 10.3348/kjr.2007.8.5.365.

16. Odabaş S, Sayar F, Güven $G$ et al. Separation of mesenchymal stem cells with magnetic nanosorbents carrying CD105 and CD73 antibodies in flow-through and batch systems. J Chromatogr B. 2008; 861 (1): 74-80. DOI: 10.1016/j.jchromb.2007.11.017.

17. Ito A, Hibino $E$, Honda $\mathrm{H}$ et al. A new methodology of mesenchymal stem cell expansion using magnetic nanoparticle. Biochem Eng J. 2004; 20 (2-3): 119-25. DOI: 10.1016/j.bej.2003.09.018.

18. Hsiao JK, Tai M-F, Chu H-H et al. Magnetic nanoparticle labeling of mesenchymal stem cells without transfection agent: cellular behavior and capability of detection with clinical $1.5 \mathrm{~T}$ magnetic resonance at the single cell level. Magnet Reson Med. 2007: 71724. DOI: $10.1002 / \mathrm{mrm} .21377$.

19. Zhu J, WuX, Zhang HL. Adult Neural Stem Cell Therapy: Expansion In Vitro, Tracking In Vivo and Clinical Transplantation. Curr Drug Targets. 2005; 6 (1): 97-110. DOI: 10.2174/1389450053345055.

20. Petrova EA, Drazhina NP, Semenova EM, Vorobyova SA. Primenenie magnitnyh nanochastic dlja markirovanija mezenhimal'nyh stvolovyh kletok. Vestnik BGU. Serija 2. 2012; (3): 54-9.

21. Drazhina NP, Petrova EA, Semenova EM, Vorobyova SA, avtory. Uchrezhdenie obrazovanija «Belorusskij gosudarstvennyj medicinskij universitet", Uchrezhdenie Belorusskogo gosudarstvennogo universiteta «Nauchno-issledovatel'skij institut fiziko-himicheskih problem", patentoobladateli. Koncentrat dlja poluchenija sredstva vital'noj markirovki mezenhimal'nyh stvolovyh kletok. Patent RB 17804. 15.02.2012. 